\title{
INFLUENCE OF NUMBER OF IMPELLER AND DIFFUSER BLADES ON THE PRESSURE RECOVERY OF CENTRIFUGAL FAN
}

\author{
Madhwesh $\mathbf{N}^{1}$, Manjunath M. $\mathrm{S}^{2}$, K.Vasudeva Karanth ${ }^{3}$ \\ ${ }^{l}$ Department of Mechanical \& Mfg. Engineering, Manipal Institute of Technology, Manipal, Karnataka, India \\ ${ }^{2}$ Department of Mechanical \& Mfg. Engineering, Manipal Institute of Technology, Manipal, Karnataka, India \\ ${ }^{3}$ Corresponding Author, Department of Mechanical \& Mfg. Engineering, M. I. T., Manipal, Karnataka, India
}

\begin{abstract}
Impeller is a very important element in rotating devices to deliver energy to/from the fluid. The diffusers are essential for effective transformation of the kinetic power produced by the rotor in a centrifugal fan. Hence the flow in the impeller and diffuser passages is the important phenomenon in optimizing the performance. These impeller and diffuser flow passages are the most complex regions to predict the flow behavior. With the advanced development of Particle Image Velocimetry as well as convenient numerical CFD tools, it has become possible to reach at an accurate result well-matched with the real behavior of the flow. Hence, in this work moving mesh technique is used to get a numerical solution for the estimation of actual flow manner. Numerous research works have been done recently to get the physics of fluid flow through impeller and diffuser, both numerically and experimentally. But it is found from the literature that the study on the performance of the fan by changing the number of impeller and diffuser blades together in a combination has not been the emphasis of attention in these works. Hence a numerical analysis has been carried out in this paper to comprehensively lookout the fluid interaction in impeller-diffuser as well as to envisage the flow behavior of the fan by changing the number of impeller and diffuser blades together in combination. For the same number of impeller blades, it is found from the analysis that a higher static pressure rise coefficient is achieved at the outlet of the fan for smaller number of diffuser blades. It is also found that larger the number of impeller blades, larger is the static pressure rise coefficient for the same number of diffuser blades, hence performance gets improved.
\end{abstract}

Key Words: Unsteady flow, Recirculation zone, Turbulence, Impeller vane, Diffuser vane, Static pressure rise.

\section{INTRODUCTION}

Flow pattern in centrifugal devices such as a centrifugal pump, centrifugal compressors and centrifugal fans found to be uneven having flow separation and recirculation zones in the flow passages. Hence many researchers contributed to increase the efficiency of the fan by novel approaches both numerically and experimentally. Zhang Lei and others [1] investigated the three-dimensional unsteady field of flow in a centrifugal fan by hindering the stall commencement, which involved blowing air at the inlets of the three impeller passages. The safety margin of the centrifugal fan was prolonged by $13 \%$, and stability improvement effect was attained. This new active control method for rotating stall presented an appreciated means to confirm the safe operation of a centrifugal fan. Pin Liu and others [2] examined the outcome of inlet bell mouth of semi-opened type axial fan on its performance and flow fields around rotor with six kinds of bell mouth size. The pressure-rise near best efficiency point became small with the bell mouth size declining. The value of maximum efficiency became small as the bell mouth size reduced. Choon Man Jang and others [3] showed the performance enrichment study of a regenerative blower. Two design variables, bending angle of the impeller and blade thickness of the impeller tip, were presented to improve the blower performance. It was found that the thickness of impeller tip was effective to raise the blower efficiency in the blower. Pressure was amplified up to $2.8 \%$ compared to the reference blower at the design flow condition. Efficiency was also enhanced up to $2.98 \%$ compared to the reference one. A portion of the analysis done in the present paper is authenticated with a journal by Meakhail and Park [4], in which the authors investigated the interaction of fluid in the flow passages in a centrifugal fan. Variables which govern the flow through the passages of rotor and stator were recognized and a well matched result was obtained using CFD analysis of the centrifugal fan. A three dimensional flow field of multi-blade centrifugal fan was replicated with Fluent by HUANG Chuang and others [5]. The impact of typical geometric parameters on fan's flow rate and noise was studied. Coupled algorithm, MUSCL discretization scheme and steady RANS equations were used to solve the internal flow field of the fan. FW-H acoustic model combined with the large eddy simulation was used to compute flow noise of the fan. The results showed that calculation data under different operating conditions match with the experimental results. They also perceived that fan tongue radius, number of blades and blade's import settling angle have noteworthy effects on flow rate and flow noise. The results delivered a reference to the best design of multi-blade centrifugal fan.

Daniel Swain and others [6] used Centrifugal compressor blade trimming method for the purpose of improvement of performance. Several methods of impeller blade trimming were done to obtain various flow rates and the pressure ratio. They found that, for same amount of flow coefficient, by shifting the shroud contour in the axial direction, head 
coefficient was reduced after trimming the impeller blades. In the meridional direction of the passage, trimming is restricted by choking and hence a reduction up to $15 \%$ in head coefficient was achieved.

Aerodynamic performance of a centrifugal compressor was investigated under various casing treatment configurations of stepped tip gap type numerically by Reza TaghaviZenouz [7]. This technique was introduced for the improvement of stall margin and efficiency. Navier-Stokes equations were solved $\mathrm{k}-\varepsilon$ turbulence model. Different geometries of the compressor stepped tip gap were examined to obtain the optimum configuration. They found that the tip leakage flow strength was deteriorated by stepped tip gap.

Ahti Jaatinen Värri and others [8] studied the effect of the width of the vaneless diffuser on the stage performance and flow fields of a centrifugal compressor both numerically and experimentally. The diffuser flow area from the shroud side was reduced to change diffuser width. Various diffusers with varying width were studied with numerical simulation. They found that this change of width reduced losses in the impeller. Also, it was shown that a highly non uniform flow and separation of flow was achieved near the shroud with the higher width reduction.

\section{NOMENCLATURE}

j : Universal Variable

$\mathrm{N} \quad$ : Universal Variable

$\mathrm{t} \quad$ : Time in $\mathrm{s}$

$\Delta \mathrm{t} \quad$ : Time Step

$\mathrm{p} \quad$ : Pressure (Static) $(\mathrm{Pa})$

pt $\quad$ : Pressure $($ Total $)(\mathrm{Pa})$

$\gamma \quad$ : The advance angle of a given rotor vane to its next neighboring vane location (Deg.),

$\alpha \quad$ : Static Pressure Recovery Coefficient

$\beta \quad$ : Total Pressure Loss Coefficient

Subscripts

1: Rotor inlet;

2: Rotor exit;

3: Volute Casing exit.

Suffix:

1 - Fan Inlet,

2 - Rotor exit,

3 - Volute Exit

\section{COMPUTATIONAL MODELING}

\subsection{Geometry and Grid Generation}

The model of the centrifugal fan with single stage is built which has an inlet region, an impeller, a diffuser, and a volute casing (figure 1). Two dimensional, backward swept, thirteen bladed impeller is used. A thirteen bladed diffuser, a stationary element, is located at the exit of the impeller. Blade thickness was considered to be $2 \mathrm{~mm}$. This arrangement is used as base configuration in this paper.

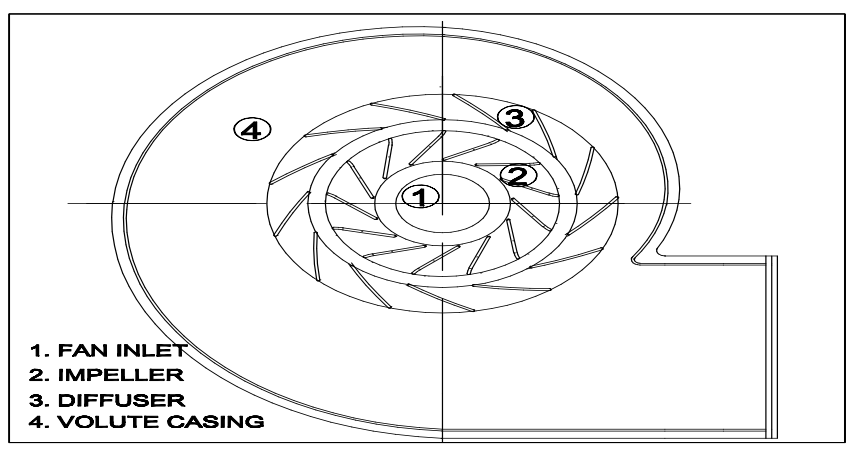

Fig.1. Centrifugal Fan Stage

The specifications of the fan stage are demonstrated in Table 1. The technical paper by Meakhail and Park [4] is the basis for geometric modeling in the current work.

Table 1: Specifications of Centrifugal Fan

\begin{tabular}{|l|l|}
\hline Rotor inlet diameter & $240 \mathrm{~mm}$ \\
\hline Rotor outlet diameter & $400 \mathrm{~mm}$ \\
\hline Diffuser inlet diameter & $460 \mathrm{~mm}$ \\
\hline Diffuser outlet diameter & $600 \mathrm{~mm}$ \\
\hline Exit flange width of Volute & $450 \mathrm{~mm}$ \\
\hline Rotor inlet blade angle & $30^{\circ}$ \\
\hline Rotor outlet blade angle & $76^{\circ}$ \\
\hline Diffuser inlet blade angle & $23^{\circ}$ \\
\hline Diffuser outlet blade angle & $38^{\circ}$ \\
\hline Number of impeller blades & 13 \\
\hline Number diffuser blades & 13 \\
\hline RPM of the fan & 2880 \\
\hline
\end{tabular}

Present analysis is for unsteady fluctuation; unstructured meshing system is executed for creating sliding mesh arrangement and is carried out using the CFD code. The ultimate size of the element is restricted to elements with a size of $3 \mathrm{~mm}$. Hence an element size of maximum of $2 \mathrm{~mm}$ was done to form grid independency test. The differences in the results obtained were less than $1 \%$ and hence to achieve lesser iteration time, elements with size not more than $3 \mathrm{~mm}$ size is accepted. Figure 2 shows a part of fine meshed domain of flow.

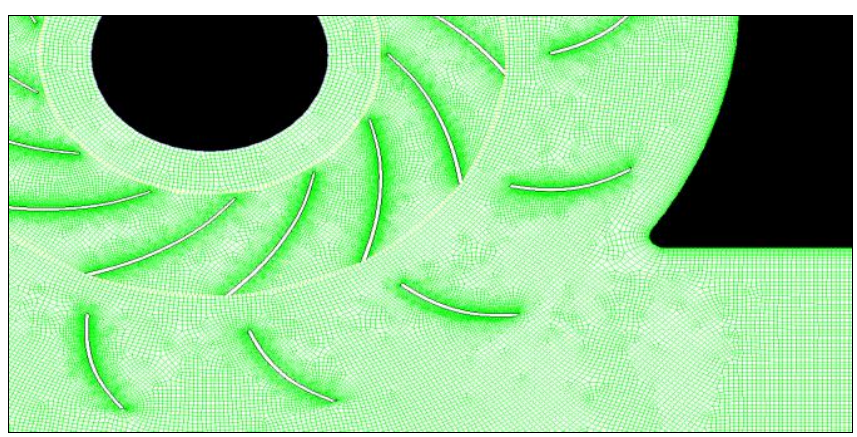

Fig.2. Portion of the mesh of the computational domain

\subsection{Unsteady Calculation}

CFD code is incorporated to solve two-dimensional, URANS with marching time analysis. An inlet velocity of $5 \mathrm{~m} / \mathrm{s}$ is imposed at the inlet. This velocity is the design point velocity for the base configuration of centrifugal fan. At the 
exit of the fan a zero gradient outflow condition of all flow variables is imposed for a completely developed flow. K- $\varepsilon$ model is used to simulate turbulence. 5\% turbulence intensity is assumed and a turbulent length scale of $0.5 \mathrm{~m}$ is adopted. This length scale value is the cube root of the domain volume. A second order implicit velocity, unsteady formulation is used and the solver is pressure based. SIMPLE algorithm is used for pressure-velocity coupling and power law scheme is used for discretization. This power law scheme established by Patankar [9] is used in the analysis because of the fact that it is computationally not so rigorous and on the whole gives noble depiction of the exponential performance when peclet number go beyond 2.0 .

The relative location amongst the rotor and the stator is updated with each time step. The impeller domain is established to sliding mesh. The time step $\Delta \mathrm{t}$ is fixed to $5.78703 \mathrm{e}-5$, which is equivalent to the progress of the rotor by $\Delta \gamma=1^{\circ}$ per time step for a speed of $2880 \mathrm{rpm}$ to establish a stable benchmark. 20 iterations are given for each time to reduce all extreme residuals to significance beneath 10-6. Since the flow environment is unsteady, it is compulsory to carry out the numerical analysis till the transient oscillations of the flow field become time periodic. In the current study, this has been attained after two whole revolutions of the impeller. The pressure and velocity fluctuations at each salient location are obtained as time and area weighted average values in the flow domain and are documented corresponding to every rotational movement of the impeller by time step progression. Two non-dimensional parameters, namely, static pressure rise coefficient $\alpha$ and the total pressure loss coefficient $\beta$ are used to quantify the improvement in the output of the fan. These $\alpha$ and $\beta$ can be found out using Eq. (1) and Eq. (2) respectively.

$$
\begin{aligned}
& \alpha=\frac{1}{N} \sum_{j=1}^{j=N}\left(\frac{p_{3}-p_{2}}{p_{\mathrm{t} 2}-p_{2}}, t_{\text {initial }}+j \Delta t\right) \\
& \beta=\frac{1}{N} \sum_{j=1}^{j=N}\left(\frac{p_{\mathrm{t} 2}-p_{\mathrm{t} 3}}{p_{t 2}-p_{2}}, t_{\text {initial }}+j \Delta t\right)
\end{aligned}
$$

\subsection{Geometric Modeling of Configuration with}

\section{various numbers of impeller and diffuser blades}

Table 2 gives the information regarding the various models used in this numerical work.

Table 2: Specifications of Geometric Configurations

\begin{tabular}{|c|c|c|}
\hline $\begin{array}{c}\text { Model } \\
\text { Name }\end{array}$ & $\begin{array}{c}\text { No. of Impeller } \\
\text { blades }\end{array}$ & $\begin{array}{c}\text { No. of diffuser } \\
\text { blades }\end{array}$ \\
\hline M1 & 13 & 13 \\
\hline M2 & 12 & 12 \\
\hline M3 & 12 & 13 \\
\hline M4 & 12 & 14 \\
\hline
\end{tabular}

\begin{tabular}{|l|l|l|}
\hline M5 & 13 & 12 \\
\hline M6 & 13 & 14 \\
\hline M7 & 14 & 12 \\
\hline M8 & 14 & 13 \\
\hline M9 & 14 & 14 \\
\hline
\end{tabular}

\section{RESULTS AND DISCUSSIONS}

It is seen from figure 3 that configurations M2, M5, M7, M8 and M9 show performance improvement in terms of overall static pressure recovery coefficient when it is compared with the base configuration M1. However configurations M3, M4 and M6 show poor static pressure recovery of the fan. The variations in the values of total pressure loss coefficient are shown in Fig 4. These lower values also justify the performance improvement of fan for the configurations M2, M5, M7, M8 and M9.

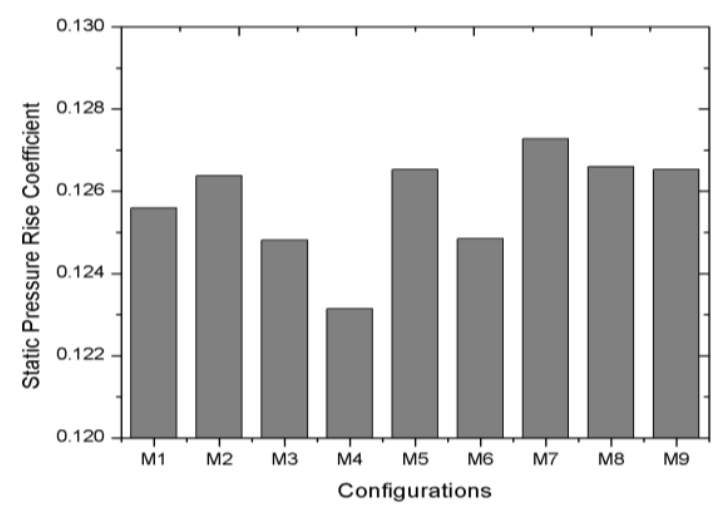

Fig.3. Static pressure rise coefficient across the fan for different configurations

The instantaneous streamline plots shown in figures 5, 6 and 7 provide the technical justification for the above implications from the bar charts. It can be observed from figure that more number of impeller blades is helpful to achieve better blade loading and through flow in the impeller passages. Hence the diffuser will get a through flow from the impeller and improves the static pressure recovery.

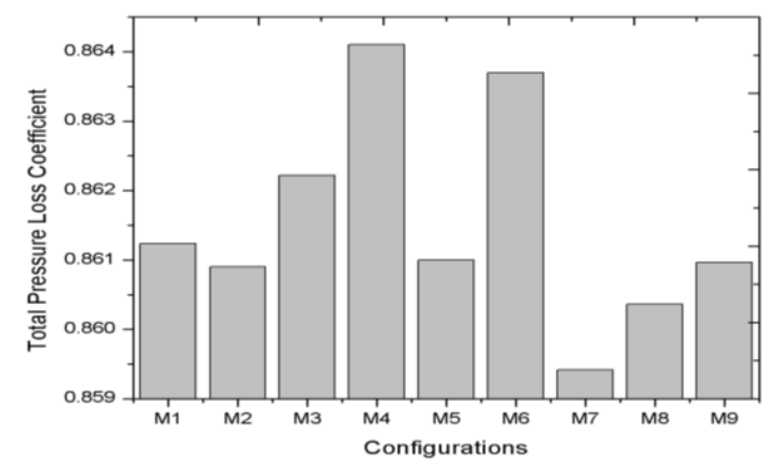

Fig.4. Total pressure loss coefficient across the fan for different configurations 
The quality of flow behavior fluctuates widely when the fluid flows between a large numbers of diffuser blade passages. Flow separation may be possible near these blades to create a rotating stall and hence the device may perform adversely. Hence it is recommended to arrange for a smaller number of diffuser blades to avoid such a possibility of stalling. The extent of distribution of fully developed flow for each vane passage becomes larger when the number of diffuser blades is reduced. The amount of diffusion decreases when the number of diffuser blades is increased and hence the overall performance deteriorates. At the same time, the flow losses tend to fall due to better guidance. The diffusing region will be narrower and diffusion angle also falls for the increase in number of diffuser blades, leading to the development of eddy zones. Hence volute will receive a non-uniform flow structure as a result of this flow disruption. This leads to higher amount of total pressure loss in the volute region.

\section{CONCLUSION}

The below mentioned inferences are obtained from the analysis carried out in this work:

- $\quad$ Static pressure recovery is depending on the number of impeller blades. Maximum pressure recovery is corresponding to 14 blades for impeller in the present analysis.

- Static pressure recovery is also depending on the number of diffuser blades. Maximum pressure recovery is corresponding to 12 blades for diffuser in the present analysis.

- Higher the number of impeller vane higher is the pressure recovery because of better blade loading effect.

- Higher the number of diffuser vane lower is the pressure recovery due to the narrow diffusing space.

\section{ACKNOWLEDGMENT}

The authors wish to thank Manipal University, Manipal, India and Department of Mechanical and Manufacturing Engineering of Manipal Institute of Technology, Manipal, India for the computational facilities provided and is appreciatively acknowledged.

\section{REFERENCES}

[1]. Zhang Lei, Wang Rui, Yuan Wei and Wang Songling, "Simulation of air jets for controlling stall in a centrifugal fan", Proc IMechE Part C:J Mechanical Engineering Science, 2014.

[2]. Pin Liu, Norimasa Shiomi, Yoichi Kinoue, Toshiaki Setoguchi and Ying-zi Jin, "Effect of Inlet Geometry on Fan Performance and Inlet Flow Fields in a Semiopened Axial Fan", International Journal of Fluid Machinery and Systems, Vol. 7, No. 2, April-June 2014.

[3]. Choon-Man Jang and Hyun-Jun Jeon, "Performance Enhancement of $20 \mathrm{~kW}$ Regenerative Blower Using Design Parameters", International Journal of Fluid Machinery and Systems, Vol. 7, No. 3, July 2014.

[4]. Meakhail, T. and Park, S.O., A Study of ImpellerDiffuser-Volute Interaction in a Centrifugal Fan, ASME Journal Turbomachinery, 2005, 127, pp. 84 90.

[5]. HUANG Chuang, LI Daijin, "The Performance Analysis and Optimal design of Fan with Fluent", IEEE, 2014.

[6]. Daniel Swain and Abraham Engeda, "Effect of impeller blade trimming on the performance of a 5.5:1 pressure ratio centrifugal compressor", Proc IMechE Part C:J Mechanical Engineering Science, 2014.

[7]. Reza Taghavi-Zenouz, Ehsan Solki and Hadi Afshari., "Stall margin improvement of a centrifugal compressor utilizing various stepped tip gap configurations", Proc IMechE Part C:J Mechanical Engineering Science, 2014.

[8]. Ahti Jaatinen-Värri, Aki Grönman, Teemu TurunenSaaresti, and Jari Backman, "Investigation of the Stage Performance and Flow Fields in a Centrifugal Compressor with a Vaneless Diffuser", International Journal of Rotating Machinery, Volume 2014, Article ID 139153, 2014.

[9]. Fluent 16.1, Fluent Inc., Cavendish Court Lebanon, NH, 03766, USA.

[10]. Patankar, S.V., "Numerical Heat Transfer and Fluid Flow", Tailor and Francis, pp. 90-92, 1980.

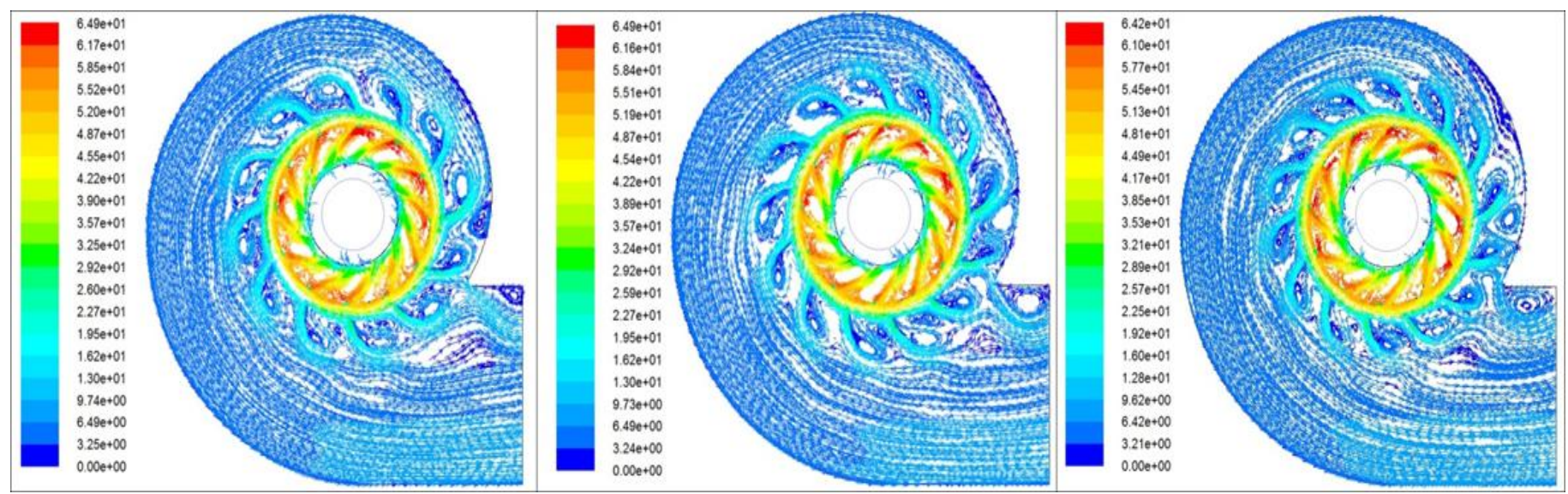

Fig.5. Instantaneous streamline plots for configurations M2, M3 and M4 


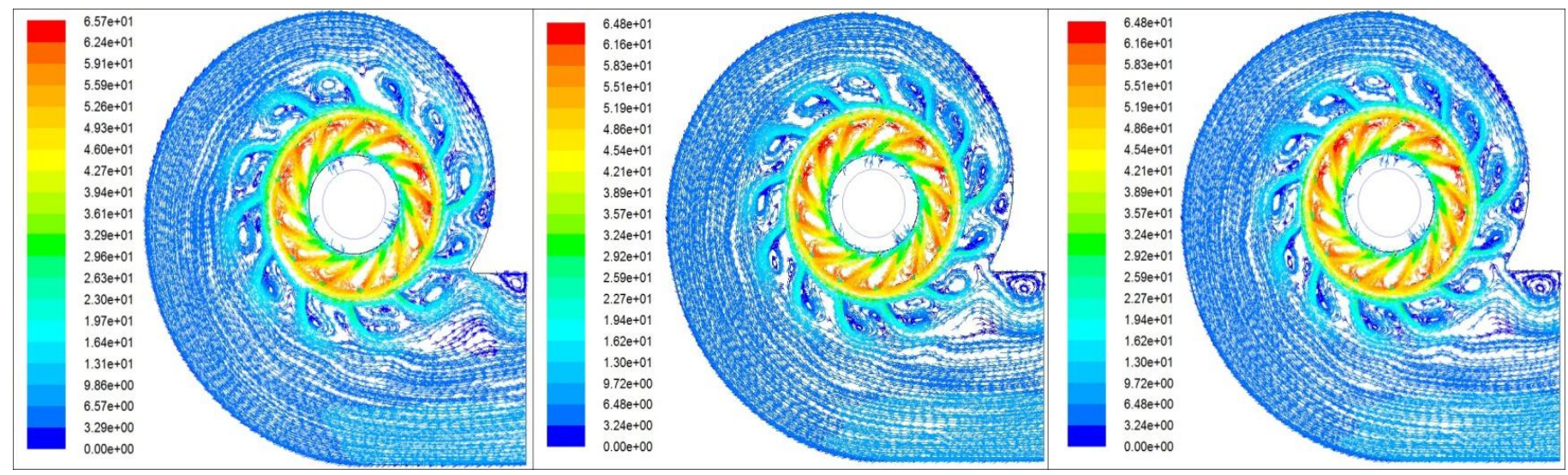

Fig.6. Instantaneous streamline plots for configurations M1, M5 and M6

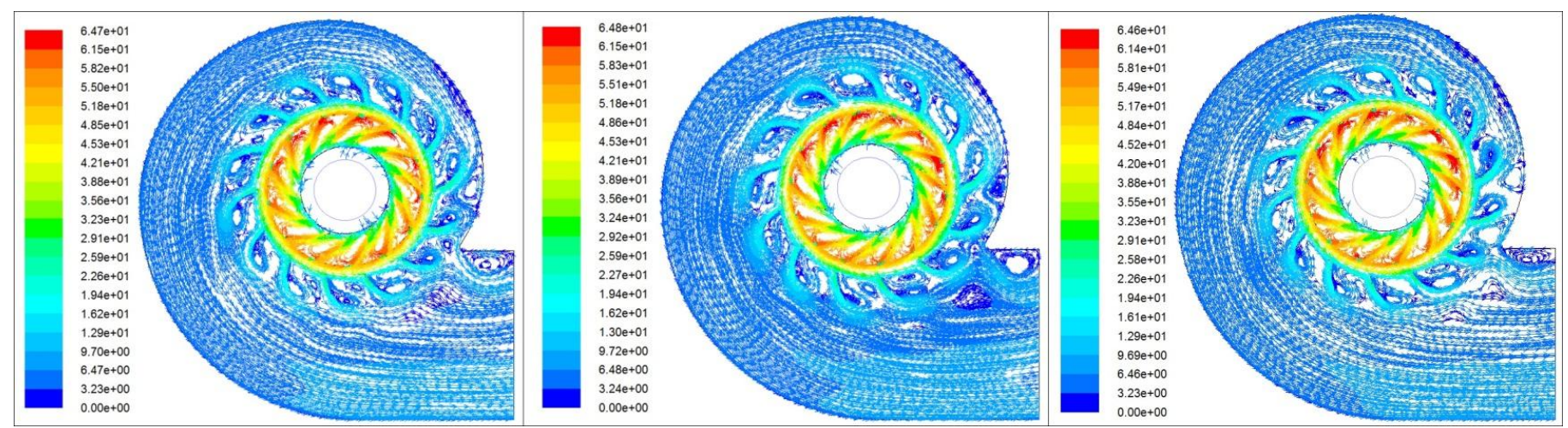

Fig 7. Instantaneous streamline plots for configurations M7, M8 and M9

\section{BIOGRAPHIES}

[1]. Mr. Madhwesh N. is working as a faculty in the Department of Mechanical and Manufacturing Engineering of Manipal Institute of Technology, Manipal University, Manipal. Email: madhwesh.n@gmail.com.

[2]. Mr. Manjunath M S. is working as a faculty in the Department of Mechanical and Manufacturing Engineering of Manipal Institute of Technology, Manipal University, Manipal. Email: manjunathnitc@gmail.com.

[3]. Dr. K. Vasudeva Karanth is working as a faculty in the Department of Mechanical and Manufacturing Engineering of Manipal Institute of Technology, Manipal University, Manipal. Email: kvkaranth@gmail.com. 